\title{
Antimicrobial activity of sequential extracts from leaves of Cassia nodosa bunch
}

\author{
Sharma, R. A. ${ }^{*}$ Richa Bhardwaj and Pallavi Sharma \\ Plant Physiology and Biochemistry Laboratory, Department of Botany, University of Rajasthan, Jaipur, Rajasthan, India.
}

Accepted 27 May, 2013

\begin{abstract}
The present study deals with the antimicrobial activity of the sequential extracts (petroleum ether, benzene, acetone, chloroform, ethanol, water, etc.) of the leaves of Cassia nodosa carried out against certain bacteria which are: Staphylococcus aureus, Salmonella typhi, Escherichia coli, Pseudomonas aeroginosa and fungi including, Aspergillus flavus, Aspergillus niger, Fusarium moniliformae and Rhizoctonia bataticola using disc diffusion technique. Results showed that most of the extracts were effective against all the test microorganisms. The minimum inhibitory concentrations of the extracts of chloroform, benzene, acetone and ethanol were found to be $2 \times 10^{4} \mu \mathrm{g} / \mathrm{ml}$, while the petroleum ether and water showed no inhibition. The results of the study provide scientific basis for the use of the plant extracts in the treatment of fungal and bacterial diseases. Therefore, the various active principles possessing antimicrobial activity may be extracted from the leaves of $C$. nodosa by various organic solvents.
\end{abstract}

Key words: Cassia nodosa, antimicrobial activity, petroleum ether, bezene, chloroform, acetone, ethanol, water, bacteria, fungi.

\section{INTRODUCTION}

One big concern the world is facing is the development of resistance to the antibiotics in current clinical use. Traditional medicinal methods, especially the use of medicinal plants, still play a vital role to cover the basic health needs in the developing countries, and moreover, the use of herbal remedies has risen in the developed countries in the last decade. Natural products are still major sources of innovative therapeutic agents for various conditions, including infectious diseases (Selim et al., 2013). In this regard, Cassia species have been of keen interest in phytochemical and pharmacological research due to their excellent medicinal values. Different classes of natural products, possessing potent physiological and pharmacological activities have been isolated from Cassia species, and they include anthracene derivatives, flavonoids and polysaccharides (Jain et al., 1997). Some of these compounds have been shown to possess considerable antimicrobial activity (Ayo et al., 2007).

The world health organization (WHO) highly appreciated the conventional medical practices for treatment and precautionary measure of various diseases (Barkatullah et al., 2013). Cassia species are well known in folk medicine for their laxative and purgative activities (Eluojoba et al., 1999). Cassia nodosa is one of the beautiful fast growing ornamental exotic plants with pink flowers found along the roadsides and gardens in Jaipur. It is widespread in world's tropical and sub-tropical regions. Phytochemically, $C$. nodosa have been studied for fixed oils of the seeds (Rizvi et al., 1968),

*Corresponding author. E-mail: sharma_ra2007@yahoo.com. Tel: 09461164336. 
glactomann and nodoside, a new anthraquinone glycoside from the flowers (Rizvi et al., 1971a, b.) and bark (Yadav et al., 1998).

The phytochemical and cytotoxic screening of the plant has been carried out earlier, and the four crude extracts showed strong cytotoxic activity. The extracts were found to be positive for carbohydrate, anthracene derivatives, cardiac and saponin glycosides as well as alkaloid. The aim of the present study is to investigative the antimicrobial activity of the various sequential extracts of the leaves of $C$. nodosa in different solvents.

\section{MATERIALS AND METHODS}

\section{Plant}

The leaves of $C$. nodosa were collected from Central Park, Jaipur. Leaves were washed with tap water, dried at room temperature and ground to fine powder. The species specimen was authenticated and submitted in herbarium, Department of Botany, University of Rajasthan, Jaipur, Rajasthan, India and got the voucher specimen No. RUBL15487.

\section{Extraction procedure}

Powdered $50 \mathrm{~g}$ of $C$. nodosa leaves were soxhlet extracted with petroleum ether, benzene, chloroform, acetone, alcohol, and water successively for 36 to $48 \mathrm{~h}$. Each of the resultant extract was filtered, dried in vauco and stored at $4^{\circ} \mathrm{C}$, until screened for antimicrobial activity and weighed to calculate the extractive value (\%) on dry weight basis. Later, following the established protocols (Paech and Tracey, 1955), each of the test samples was used against test microorganisms.

\section{Test microorganisms}

Standard strains of Staphylococcus aureus, Salmonella typhyi, Escherichia coli and Pseudomonas aeruginosa were obtained from microbiology Lab, SMS medical college College, Jaipur and Aspergillus flavus, Aspergillus niger, Fusarium monilliformae and Rhizoctonia betaticola were obtained from seed pathology lab, Department of Botany, University of Rajasthan, Jaipur (Figure 1).

\section{Antimicrobial screening}

The disc diffusion method was used to determine the antimicrobial activities of the crude extracts of petroleum ether, benzene, acetone, chloroform, ethanol and water using standard procedure (Ali et al., 1999; Crockett et al., 1992). The discs of $6 \mathrm{~mm}$ size were prepared using Whatmann's filter paper no. 1. Solutions of varying concentrations ranging from $1.0 \times 10^{4}$ to $5.0 \times 10^{4} \mathrm{mg} / \mathrm{ml} /$ disc were prepared. The treated discs were air dried at room temperature to remove any residual solvent which might interfere with the determination, sterilized and inoculated. For the cultivation of bacteria, nutrient broth medium (NBM) was prepared using $8 \%$ nutrient broth (Difco) in distilled water and agar-agar and sterilized at $15 \mathrm{lbs}$ psi for 25 to $30 \mathrm{~min}$. However, for the cultivation of fungi, potato dextrose agar medium was prepared and the test fungi were incubated at $27^{\circ} \mathrm{C}$ for $48 \mathrm{~h}$, and the cultures were maintained on same medium by regular sub-culturings. To prepare the test plates,
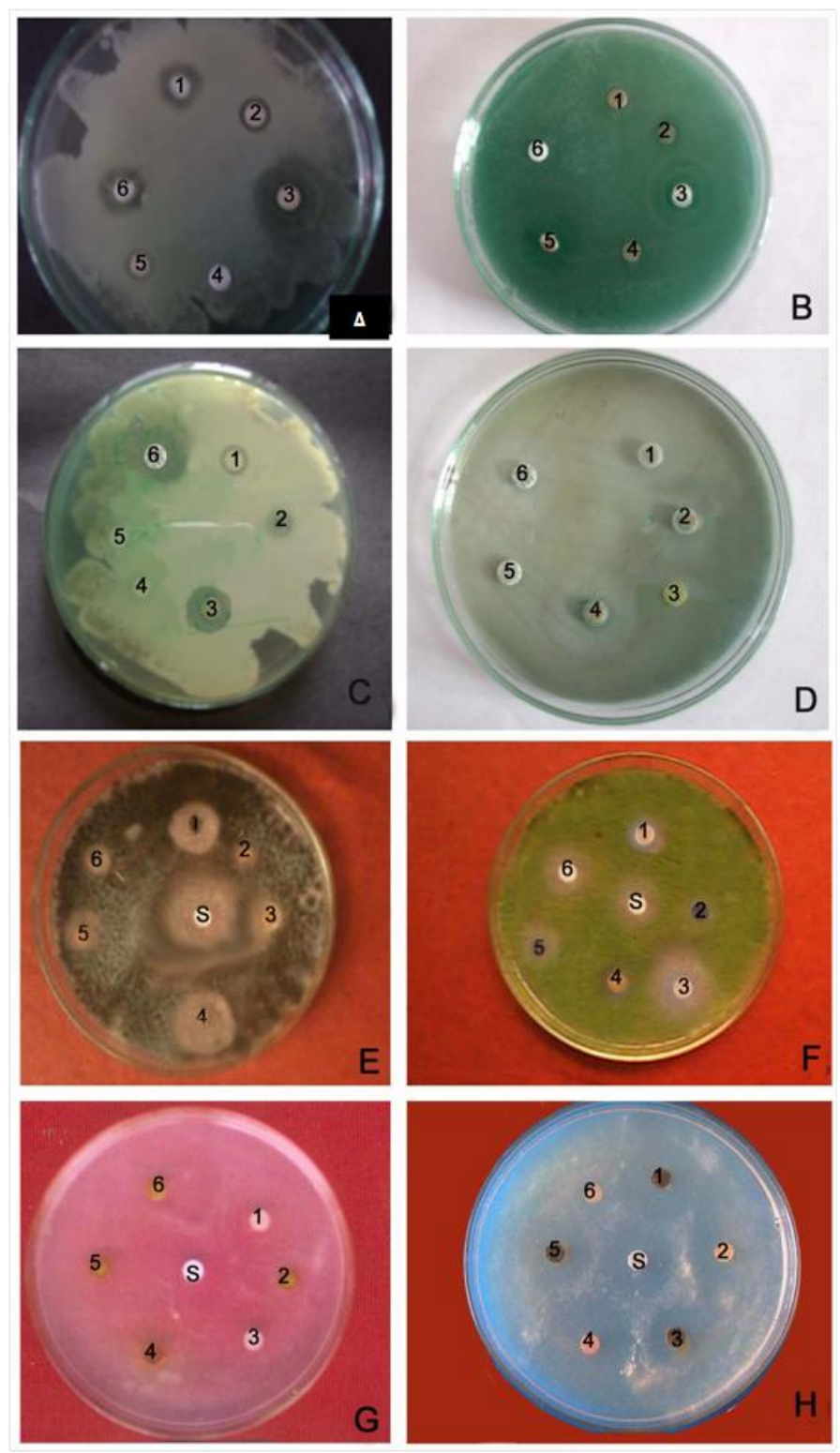

Figure 1. Photographs of antimicrobial activity of sequential extracts of leaves of selected Cassia nodosa. Bacteria $(A=E$. coli, $\mathrm{B}=\mathrm{S}$. aureus, $\mathrm{C}=P$. aeruginosa, $\mathrm{D}=\mathrm{S}$. typh $)$; Fungi $(\mathrm{E}=A$. flavus, $\mathrm{F}=A$. niger, $\mathrm{G}=\mathrm{R}$. bataticola, $\mathrm{H}=\mathrm{F}$. moniliforme, $\mathrm{S}=$ Standard). 1 = Petroleum ether extract of leaves, 2 benzene extract of leaves, 3 = chloroform extract of leaves, $4=$ acetone extract of leaves, $5=$ alcohol extract of leaves, $6=$ aqueous extract of leaves.

in both bacteria and fungi, 15 to $20 \mathrm{ml}$ of the respective medium was poured into the petri dishes under aseptic conditions and used for screening. The different test organism were proceeded separately using a sterile swab over sterilized culture medium plates and the zone of inhibition were measured around sterilized dried discs of whatman no. 1 paper. These plates were initially placed at low temperature for $1 \mathrm{~h}$ so as to allow the maximum diffusion of compounds from the test disc into the agar plate and later incubated at $37^{\circ} \mathrm{C}$ for $24 \mathrm{~h}$ in case of bacteria and $48 \mathrm{~h}$ for 
Table 1. Results zone of inhibition of Cassia nodosa leaves against microorganism.

\begin{tabular}{lcccccc}
\hline \multirow{2}{*}{ Text microorganism } & \multicolumn{7}{c}{ Diameter of zone of inhibition (mm) } \\
\cline { 2 - 7 } & Petroleum ether & Benzene & Acetone & Chloroform & Ethanol & Water \\
\hline Bacteria & 07 & 13 & 14 & 17 & 16 & 06 \\
Staphylococcus aureus & 04 & 10 & 12 & 12 & 13 & 00 \\
Salmonella typhi & 07 & 13 & 24 & 21 & 10 & 07 \\
Pseudomonas aeurginosa & 04 & 11 & 20 & 12 & 16 & 06 \\
Escherichia/ coli & & & & & & \\
& & & & & & \\
Fungi & 00 & 18 & 20 & 16 & 18 & 00 \\
Aspergillus niger & 00 & 15 & 18 & 23 & 21 & 00 \\
Aspergillus flavus & 03 & 11 & 12 & 15 & 17 & 00 \\
Fusarium moniliformae & 00 & 10 & 09 & 10 & 11 & 00 \\
Rhizoctonia bataticola & & & & & & \\
\hline
\end{tabular}

fungi, after which the zone of inhibition could be easily observed. Five replicates of each text extract were examined and the mean values were then referred.

\section{Microdilution test}

The minimum inhibitory concentrations (MICs) were determined using 96-well microtitre plates. The bacterial suspension was adjusted with sterile saline to a concentration of $1.0 \times 10^{7} \mathrm{cfu} / \mathrm{ml}$. Compounds to be investigated were dissolved in broth LB medium $(100 \mu \mathrm{l})$ with bacterial inoculums $\left(1.0 \times 10^{5} \mathrm{cfu}\right)$ to achieve the wanted concentrations $(1 \mathrm{mg} / \mathrm{ml})$. The microplates were incubated for $24 \mathrm{~h}$ at $48^{\circ} \mathrm{C}$. The lowest concentrations without visible growth (at the binocular microscope) were defined as concentrations that completely inhibited bacterial growth (MICs). The optical density of each well was measured at a wavelength of $655 \mathrm{~nm}$ by Microplate reader (Perlong, ENM8602) and compared with a blank and the positive control.

\section{RESULTS AND DISCUSSION}

Table 1 shows the results of the antimicrobial activities against the test microorganisms. The zones of inhibition for each case were measured in $\mathrm{mm}$ of the diametrical sections of the respective sequential extracts. Table 2 shows the results of MIC. From the results, it was observed that the chloroform, benzene, acetone and ethanol had very high growth inhibitory effects on all microorganisms. The MIC values for the chloroform extract on S. aureus, E. coli, $P$. aeruginosa, A. flavus and $A$. niger was found to be $2 \times 10^{4} \mu \mathrm{g} / \mathrm{ml}$, while for $S$. typhyi, $F$. monilliformae and $R$. betaticola the MIC value was $3 \times 10^{4} \mu \mathrm{g} / \mathrm{ml}$. The MIC value of acetone was found that $2 \times 10^{4} \mu \mathrm{g} / \mathrm{ml}$ against $S$. aureus, $P$. aeruginosa, $E$. coli, A. flavus, A. niger and for S. typhi, F. monilliformae and $R$. betaticola the MIC value was $3 \times 10^{4} \mu \mathrm{g} / \mathrm{ml}$. The MIC for the benzene and ethanol was found to be $2 \times 10^{4}$ $\mu \mathrm{g} / \mathrm{ml}$ for all the test microorganisms, except for $S$. typhi and $R$. betaticola $\left(3 \times 10^{4} \mu \mathrm{g} / \mathrm{ml}\right)$.

The petroleum ether and water extracts did not show any inhibition against the test microorganisms. Low MIC is an indication of high efficacy of the plant extract while high MIC may indicate low efficacy or possible development of resistance by the microorganisms to the antimicrobial. Reports on the antibacterial and antifungal activity have been evaluated by number of workers on the C. nodosa species (Mohtar and Sharri, 2000; Sayed et al., 2011). The test organisms used in this study are associated with various forms of human infections. Infection caused by $S$. typhi is a serious public health problem in developing countries and represents a constant concern for the food industry (Mastroeni, 2002). The results of the antimicrobial activity of the various sequential extracts were in agreement with the uses of the extract of the leaves of $C$. nodosa in traditional medicine for the treatment of bacterial and fungal diseases. Secondly, different solvents have different solubility capacities for different phytoconstituents, hence the differences in the activities of the various extracts (Majorie, 1999). The leaves of the plant were found to be a potential source of broad spectrum antibiotics. Studies are in progress to purify and characterize the active principles in the leaves.

\section{Conclusion}

Active principles possessing antimicrobial activity may be extracted from the leaves of $C$. nodosa by benzene, acetone, chloroform and ethanol. 
Table 2. Zones of inhibition of different concentration of Cassia nodosa $(\mu \mathrm{g} / \mathrm{ml})$.

\begin{tabular}{|c|c|c|c|c|c|c|c|c|c|c|c|c|c|c|c|c|c|c|c|c|c|c|c|c|c|c|c|c|c|c|}
\hline \multirow[b]{2}{*}{ Text organisms } & \multicolumn{5}{|c|}{ Petroleum ether } & \multicolumn{5}{|c|}{ Benzene } & \multicolumn{5}{|c|}{ Chloroform } & \multicolumn{5}{|c|}{ Acetone } & \multicolumn{5}{|c|}{ Ethanol } & \multicolumn{5}{|c|}{ Water } \\
\hline & $\frac{\text { ta }}{\underline{x}}$ & 京 & 亭 & $\frac{d}{x}$ & 旁 & $\frac{\text { to }}{\underline{x}}$ & 京 & 亭 & $\frac{d}{x}$ & 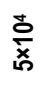 & $\frac{d}{\underline{x}}$ & 京 & 亭 & $\frac{d}{x}$ & 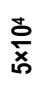 & $\frac{\text { to }}{\underline{x}}$ & 京 & 亭 & $\frac{d}{\frac{d}{x}}$ & 亮 & $\frac{t}{\underline{x}}$ & 京 & 亭 & $\frac{d}{\frac{d}{x}}$ & 毫 & $\frac{\text { ta }}{\underline{x}}$ & 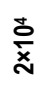 & 旁 & $\frac{d}{x}$ & 旁 \\
\hline \multicolumn{31}{|l|}{ Bacteria } \\
\hline Staphylococcus aureus & - & - & - & - & - & - & + & + & + & + & - & + & + & + & + & - & + & + & + & + & - & + & + & + & + & - & - & - & - & - \\
\hline Salmonella typhi & - & - & - & - & - & - & - & \pm & + & + & - & \pm & + & + & + & - & \pm & + & + & + & - & - & + & + & + & - & - & - & - & - \\
\hline Pseudomonas aeurginosa & - & - & - & - & - & - & + & + & + & + & - & + & + & + & + & - & + & + & + & + & - & + & + & + & + & - & - & - & - & - \\
\hline Escherichia/ coli & - & - & - & - & - & - & + & + & + & + & - & + & + & + & + & - & + & + & + & + & - & + & + & + & + & - & - & - & - & - \\
\hline \multicolumn{31}{|l|}{ Fungi } \\
\hline Aspergillus niger & - & - & - & - & - & - & + & + & + & - & - & + & + & + & - & - & + & + & + & - & - & + & + & + & + & - & - & - & - & - \\
\hline Aspergillus flavus & - & - & - & - & - & - & - & + & + & + & - & + & + & + & + & - & + & + & + & + & - & + & + & + & + & - & - & - & - & - \\
\hline Fusarium moniliformae & - & - & - & - & - & - & \pm & + & + & - & - & + & + & + & - & + & + & + & + & - & - & \pm & + & + & + & - & - & - & - & - \\
\hline Rhizoctonia bataticola & - & - & - & - & - & - & \pm & + & + & - & - & + & + & + & - & + & + & + & + & - & - & \pm & + & + & + & - & - & - & - & - \\
\hline
\end{tabular}

\section{REFERENCES}

Ali MS, Azhar I, Amtul Z, Ahmad VU, Usmanghani K (1999). Antimicrobial screening of some Caesalpiniaceae. Fitoterapia 70:299-304.

Ayo RG, Amupitan JO, Zhao Y (2007). Cytotoxicity and antimicrobial studies of $1,6,8$ - trihydroxy-3-methylanthraquinone (emodin) isolated from the leaves of Cassia nigricans Vahl. Afr. J. Biotechnol. 6(11):1276-1279.

Barkatullah BB, Muahmmad I, Niaz A, Naveed M, Rehmanullah (2013). Antispasmodic potential of leaves, barks and fruits of Zanthoxylum armatum DC. Afr. J. Pharm. Pharmacol. 7(13):685-693.

Crockett CO, Guede-Guina F, Pugh D, Vangah- Manda M Robinson J, Qlubadewo JO, Ochillo RF (1992). Cassia alata and the preclinical search for therapeutic agents for the treatment of opportunistic infections in AIDS patients, Cell Mol. Biol. 35:505-511.

Eluojoba AA, Abere AT, Adelusi SA (1999). Laxatives activities of Cassia pods sourced from Nigeria. Nig. J. Nat. Prod. Med. 3:51-53.

Jain SC, Jain R, Sharma RA, Cappasso F, Mecudo N (1997). Ethnopharmacological investigation of Cassia italica. J. Ethnopharmacol. 58(2):135-142.
Majorie MC (1999). Plant Products as Antimicrobial Agents. Clinical. Microbiol. Rev. 12:564-582.

Mastroeni P (2002). Immunity to systemic Salmonella infections. Curr. Mol. Med. 2:393-406.

Mohtar M, Shaari K (1999). Antimicrobial activity of Senna alata and Cassia javanica subsp. nodosaextracts against micro-organisms related to skin infections. J. Trop. Forest Products 6(2):218-221.

Paech K, Tracey MV (1955). Modern Methods of Plant Analysis. Vol. III. Springer-Verlag, Berlin.

Rizvi SA, Gupta PC, Kaul RK (1968). Chemical and spectral studied of nodoside. A new anthraquinone glycoside from the flowers of Cassia nodosa. Plant Med. 19(3):221-233.

Rizvi, SA, Gupta PC, Kaul RK (1971a). Chemical examination of the fixed oils from the seeds of Cassia nodosa. Plan Med. 16(3):317-322.

Rizvi, SA, Gupta PC, Kaul RK (1971b). The structure of glactomannan from the seeds of Cassia nodosa. Plant. Med. 20(10):24-32.

Sayed MME, Salah AAS, Nahas HAE, Gawad MME, Aziz MMA, Hameed ESA, Ahmed WS, Abdel-Lateef EE (2011). Austr. J. Basic Appl. Sci. 5(9):344-352

Selim SA, Abdel Aziz MH, Mashait MS, Warrad MF (2013). Antibacterial activities, chemical constitutes and acute toxicity of Egyptian Origanum majorana L., Peganum harmala L. and Salvia officinalis L. essential oils. Afr. J. Pharm. Pharmacol. 7(13):725-735.

Yadav NK, Singh BK, Kumar A (1998). A new anthraquinone from the root bark of Cassia nodosa. Asian J. Chem. 10(1):204-206. 